\title{
Anaerobic processes in activated sludge
}

Article in Water Science \& Technology · December 1998

DOI: $10.1016 / 50273-1223(98) 00166-8$

CITATIONS

24

4 authors, including:

Dirk de Beer

Max Planck Institute for Marine Microbiology

416 PUBLICATIONS 13,806 CITATIONS

SEE PROFILE
READS

24

Andreas Schramm

Aarhus University

204 PUBLICATIONS 6,962 CITATIONS

SEE PROFILE

Some of the authors of this publication are also working on these related projects:

Project Center for Electromicrobiology (CEM) View project

Metabolism, function and diversity of the nephridial symbionts of earthworms View project 


\title{
ANAEROBIC PROCESSES IN ACTIVATED SLUDGE
}

\author{
Dirk de Beer*, Andreas Schramm*, \\ Cecilia M. Santegoeds* and Helle K. Nielsen** \\ * Max Planck Institute for Marine Microbiology, Microsensor group, Celsiusstrasse \\ 1. 28359 Bremen, Germany \\ ** University of Aarhus, Department of Microbial Ecology, Ny Munkegade 540, \\ DK-8000 Aarhus, Denmark
}

\begin{abstract}
We found anoxic zones in aerated activated sludge flocs, and demonstrated denitrification under normal operating conditions. Sulfate reduction was not found. Micro-environments and microbial conversions in flocs from bulking and non-bulking activated sludge were determined with microsensors for $\mathrm{H}_{2} \mathrm{~S}, \mathrm{O}_{2}, \mathrm{NO}_{2}$ and $\mathrm{NO}_{3}$. Denitrification and sulfate reduction rates were measured with ${ }^{15} \mathrm{~N}$ - and ${ }^{35} \mathrm{~S}$-tracer techniques. We showed that under normal reactor conditions (ca. $20 \%$ air saturation) anoxic zones develop within flocs allowing denitrification. The denitrification rates amounted to $40 \%$ of the rates under anoxic conditions. At $100 \%$ air saturation no anoxic zones were found and no denitrification occurred. However, in flocs from bulking sludge (at $20 \%$ air saturation) anoxic zones were absent and denitrification did not occur. In bulking sludge only at total anoxia was denitrification found. Confocal microscopy showed that flocs from bulking sludge were much looser than those from non-bulking sludge. The absence of anoxic zones and of denitrification was attributed to the open floc structure, allowing advective oxygen transport.

Sulfate reduction was not detected in any of the sludges tested by microsensors or by tracer techniques even under anoxic conditions. This indicates that the sulfur cycle (sulfate reduction and sulfide oxidation) does not play a role in mineralization processes and bulking in activated sludge. Preliminary molecular work (in situ hybridization with the 16S-rRNA probe SRB385) indicated the presence of small amounts of sulfate reducing hacteria in all sludges. Either the probe is not specific or the sulfate reducers present are not active under reactor conditions. (c) 1998 IAWQ. Published by Elsevier Science Lid
\end{abstract}

\section{KEYWORDS}

Activated sludge; micro-environment; oxic; anoxic; microsensor; sulfate reduction; denitrification; confocal microscopy.

\section{INTRODUCTION}

In wastewater treatment plants microbial communities are retained in the reactor by accumulation in a biofilm or by gravity settling in flocs or aggregates. In these structures micro-environments can develop due to mass transfer resistance within the biomass layers. Microsensors have been successfully applied to characterize the micro-environments in biofilms, aggregates and sediments. Due to mass transfer limitations anaerobic zones have been found in well aerated biofilm systems. Thick biofilms and sediments were found to be stratified in zones where different electron acceptors $\left(\mathrm{O}_{2}, \mathrm{NO}_{3}{ }^{-}, \mathrm{SO}_{4}{ }^{-2}\right)$ are reduced (Kuhl and Jorgensen, 1992; Revsbech et al., 1988). With microsensors, denitrification and sulfate reduction rates could be determined. 
The presence of anaerobic processes in activated sludge operated under aerobic conditions may have important treatment implications. Coupled nitrification and denitrification within one floc is possible. Removal of xenobiotics can require both aerobic and anaerobic processes (Gerritse and Gottschal, 1992). Furthermore, anaerobic mineralization occurs with lower biomass yield than aerobic processes, with a favorable effect on the sludge production. A previous study on activated sludge reported the presence of sulfate reducers and methanogens (Lens et al, 1995), which was considered indicative of anoxic zones. However, direct proof for the existence of anoxic zones and anaerobic conversions was not reported. We combined microsensor techniques, physiological tests and molecular techniques to investigate the microenvironment inside flocs, to determine the presence of anaerobic processes under aerobic conditions and to assess whether anaerobic microorganisms are present. The use of microsensors in activated sludge flocs has been hampered by the difficulty of immobilizing the flocs. We used a newly developed flow-cell, which allows immobilization of fragile flocs in a laminar water jet.

\section{METHODS}

Activated sludge was obtained from municipal wastewater treatment plants in Prague, Czech Republic (WWTP) and in Bremen, Germany (WWTB), and from two lab-scale sequencing batch reactors. The 51 SBRs contained 2-3 g dry weight/l sludge, originating from the Prague municipal wastewater plant. One reactor ( $\mathrm{R} 1)$ was operated at 2 cycles per day ( $4 \mathrm{~h}$ anoxic, $8 \mathrm{~h}$ oxic), the other (R2) was operated at 1 cycle per day ( $23 \mathrm{~h}$ oxic, $1 \mathrm{~h}$ anoxic). Both were fed with artificial wastewater containing $1000 \mathrm{mg}$ COD/l peptone, $500 \mathrm{mg} \mathrm{COD} / \mathrm{l}$ ethanol, $500 \mathrm{mg} \mathrm{COD} / \mathrm{l}$ acetate, $20 \mathrm{mg} / \mathrm{P}$-phosphate and $4 \mathrm{mM} \mathrm{NaHCO}$ in tap water containing $0.8 \mathrm{mM}$ sulfate. Additionally, $400 \mathrm{mg}$ nitrate- $\mathrm{N}$ was added to $\mathrm{R} 1$.

Microprofiles were recorded in a $5 \mathrm{~cm}$ diameter Plexiglas cylinder. A stocking was glued $8 \mathrm{~cm}$ from the inlet. With a large pipette flocs were placed in this flow cell. Medium was pumped upwards with such a velocity that flocs were suspended about $1 \mathrm{~mm}$ above the netting (Plough and Jorgensen, 1997). Microsensors for oxygen (Revsbech et al, 1988), $\mathrm{H}_{2} \mathrm{~S}$ (Jeroschewski et al, 1996) nitrate and nitrite (de Beer et al, 1997) were used for profiling.

Denitrification and sulfate reduction rates were measured in a 11 batch reactor. The bulk liquid concentration was aerated (by recycling the head space gas) to $0 \%, 20 \%$ and $100 \%$ air-saturation. The oxygen concentration in the bulk was monitored continuously. For measurements of the denitrification rate ${ }^{15} \mathrm{~N}$-nitrate was added $(0.1 \mathrm{mM})$. Regularly gas was sampled from the head space for ${ }^{15} \mathrm{~N}_{2}$ analysis (Nielsen, 1992). Sulfate reduction rates were determined using ${ }^{35} \mathrm{~S}$-sulfate. Samples were taken over time and fixed in $20 \% \mathrm{Zn}$-acetate for later analyses of reduced sulfur compounds (Jorgensen, 1994). The aggregate structure was studied with confocal scanning laser microscopy after staining with FITC.

\section{RESULTS AND DISCUSSION}

The floc size was strongly influenced by hydrodynamics, and thus very sensitive to the intensity of aeration. When an activated sludge sample was aerated sufficiently vigorously that air saturation was approached, all flocs were smaller than $0.5 \mathrm{~mm}$. However, when flocs were aerated to $20 \%$ air saturation the hydrodynamic regime was much milder and larger flocs of 0.5 to $1.5 \mathrm{~mm}$ were formed. We have observed such large flocs in the aeration basins of municipal plants. We have not quantified the floc size distribution under different hydraulic regimes, but a floc size of $0.5-1.5 \mathrm{~mm}$ seems to be realistic.

Microsensor measurements. The oxygen microprofiles showed that the oxygen concentration inside the flocs of a non-bulking sludge was lower than in the bulk (Fig. 1A). If the bulk liquid is air saturated flocs are fully penetrated by $\mathrm{O}_{2}$. Then the nitrate profile indicates no consumption. However, at $20 \%$ of air saturation (common in activated sludge plants) anoxic zones develop inside flocs. Under these conditions the nitrate concentration in the flocs is lower than in the bulk, indicating denitrification.

In all flocs studied nitrite was present but at insignificant concentrations $(<2 \mu \mathrm{M})$. A clear difference was observed between flocs from bulking- and non-bulking sludge. In flocs from bulking sludge the oxygen 
profiles were not very steep (Fig. 1B). At $20 \%$ air-saturation no anoxic zones developed in the flocs. Only under total anoxic conditions did nitrate consumption in the flocs result in a steep nitrate profile. The nitrate concentration in the flocs was close to the bulk level. In none of the sludges was sulfide production detected (data not shown).

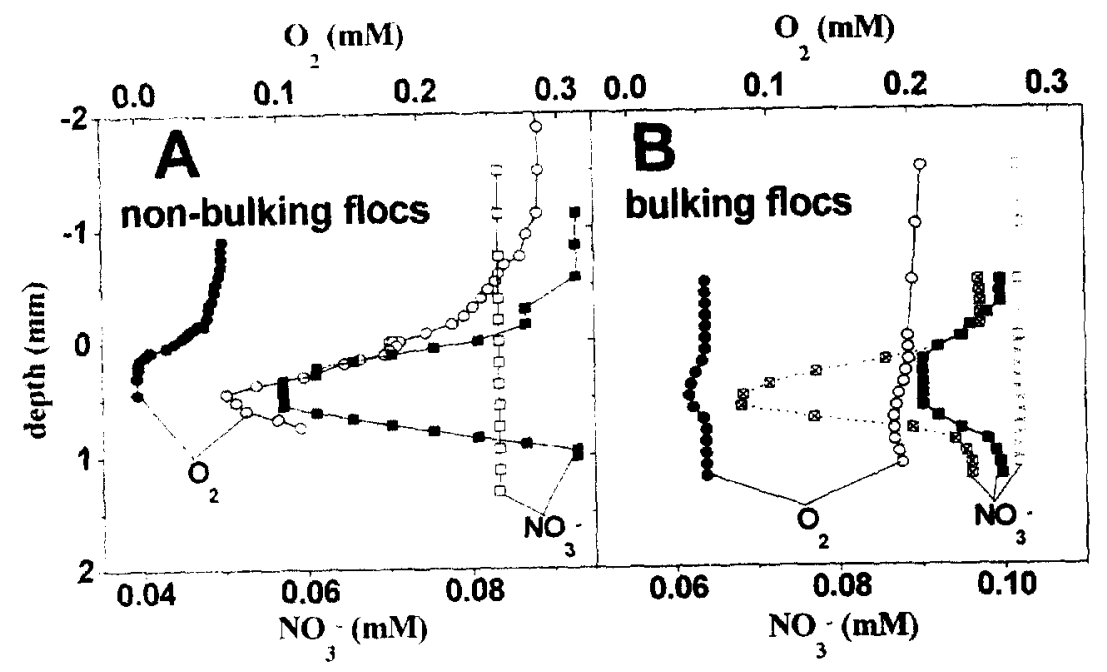

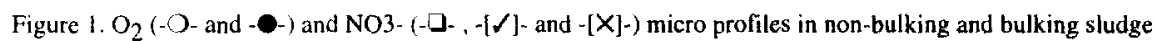
locs. Measurements were performed at $100 \%$ air saturation in the bulk liquid (open symbols), $20 \%$ of airsaturation (closed symbols) and under anoxic conditions $(-[X]-)$.

Tracer experiments. The microsensor measurements were accompanied by physiological tests for sulfate reduction and denitrification (Table 1). All tracer experiments were in good agreement with the microsensor measurements.

Table 1. Denitrification rates* in activated sludge, measured with the ${ }^{15} \mathrm{~N}$ stable isotope technique under different aeration conditions ( $\%$ air saturation)

\begin{tabular}{|c|c|c|c|}
\hline sludge type \condition & $100 \%$ & $20 \%$ & $0 \%$ \\
\hline $\mathrm{Rl}$ (non-bulking) & 0.09 & 0.97 & 2.69 \\
\hline R2 (non-bulking) & 0.11 & 0.51 & 1.67 \\
\hline WWTB (bulking) & 0.00 & 0.01 & 1.43 \\
\hline WWTP (bulking) & 0.01 & 0.02 & 0.54 \\
\hline
\end{tabular}

*numbers are in $\mu \mathrm{mol} \mathrm{N}_{2} /(\mathrm{g}$ biomass $\mathrm{x}$ minute)

For all sludges the ${ }^{15} \mathrm{~N}$-isotope tests showed very low denitrification rates at air-saturation $(100 \%)$, and denitrification under anoxia $(0 \%)$. At moderate aeration $(20 \%)$ significant differences were observed between bulking and non-bulking sludge flocs: in normal flocs denitrification was high, in bulking sludge denitrification was absent.

In none of the sludges could sulfate reduction be demonstrated even under total anoxia and in the absence of nitrate. Thus in the investigated sludges sulfate reduction is insignificant, either because sulfate reducing bacteria are absent, the conditions are unsuitable or the suitable conditions must be imposed for a longer period to allow the sulfate reducers to build up.

Molecular analysis. The DGGE patterns of the different sludges showed significantly different populations in the different sludges. In each sludge there were 15 to 19 bands, corresponding to the major inhabitants of the sludge. Only 3 bands were present in all the sludges. The other strains seemed specific for each sludge type. Using hybridization with 16S-rRNA probe SRB385 (Amann et al, 1995) small numbers of sulfate 
reducing microorganisms seem to be present in all sludges. Most likely non-specific hybridization occurs with this probe, considering the total absence of sulfate reducing activity in all the sludges tested. Currently, more specific probes are under development that will allow more accurate analysis of the sludge samples. It is not possible to design group specific probes for the phylogenetically widespread denitrifiers.

Confocal microscopy. FITC stained both cells and EPS. Due to the short incubation time, EPS was stained the most intensely. Large amounts of EPS were present in all sludges. The non-bulking flocs consisted of cells plus EPS clusters that were aggregated, leaving voids of up to $50 \mathrm{~m}$ across. The bulking sludge consisted of aggregates of loose filaments plus EPS, with more open space than in the non-bulking flocs. Possibly, the loose character of the bulking flocs allows advective flow through the flocs. This would explain why in bulking flocs the micro-environment does not strongly differ from the bulk condition, and thus why denitrification does not occur.

\section{CONCLUSIONS}

In activated sludge incubated under conditions present in activated sludge basins (reduced oxygen tensions and a mild hydraulic regime), anoxic micro-zones develop within the flocs. This only occurs in non-bulking sludge. The presence of these zones results in denitrification, but not in sulfate reduction. Molecular analysis showed that sulfate reducing bacteria seem to be present. If this is indeed the case reactor conditions are unsuitable for their activity. More detailed molecular analysis is needed for the detection of sulfate reducers.

\section{ACKNOWLEDGMENT}

This research was supported by the Körber foundation.

\section{REFERENCES}

Amann, R. L., Ludwig, W. and Schleifer, K. H. (1995). Phylogenetic identification and in situ detection of individual microbial cells without cultivation. Microbiol. Rev. 59, 153-169.

deBeer. D. Schramm, A., Santegoeds, C. M. and Kühl, M. (1997). A nitrite microsensor for profiling environmental biofilms. Appl. Environ. Microbiol. 63, 973-977.

Jeroschewski, P., Steukant, C. and Kühl, M. (1996). An amperometric microsensor for the determination of $\mathrm{H}_{2} \mathrm{~S}$ in aquatic environments. Anal Chem. 68, 435I-4357.

Jorgensen. B. B. (1994). Sulfate reduction and thiosulfate transformation in a cyanobacterial mat during a diel oxygen cycle. FEMS Microbiol. Ecol. 13, 303-312.

Kuhl, M. and Jorgensen, B. B. (1992). Microsensor measurements of sulfate reduction and sulfide oxidation in compact microbial communities of aerobic biolilms. Appt. Environ. Microbiol. 58, 1164-1174.

Lens, P. N., De Poorter. M. P., Cronenberg, C. C. and Verstracte, W. H. (1995). Sulfate reducing and methane producing bacteria in aterobic waste water treatment systems. Wat. Res. 29, 871-880.

Nielsen, L. P. (1992). Denitrification in sediment determined from nitrogen isotope pairing. FEMS Microbiol. Ecol. 86, 357-362.

Plough, H. and Jorgensen, B. B. (1997). A flow-cell for profiling algal flocs with low density. (in preparation)

Revsbech. N. P., Christensen. P. B., Nielsen. L. P. and Sorensen, J. (1988). A combined oxygen and nitrous oxide sensor for denitrification studies. Appl. Environ. Microbiol. 54, 2245-2249. 
Reproduced with permission of copyright owner. Further reproduction prohibited without permission. 